\title{
Effects of Single Vs. Multiple Sets Water-Based Resistance Training on Maximal Dynamic Strength in Young Men
}

\author{
by \\ Adriana Cristine Koch Buttelli ${ }^{1}$, Stephanie Santana Pinto ${ }^{1,2}$, \\ Maira Cristina Wolf Schoenell ${ }^{1}$, Bruna Pereira Almada', \\ Liliana Kologeski Camargo ${ }^{1 \text { (in memoriam) }}$, Matheus de Oliveira Conceição ${ }^{1}$, \\ Luiz Fernando Martins Kruel ${ }^{1}$
}

The aim of this study was to compare the effects of single vs. multiple sets water-based resistance training on maximal dynamic strength in young men. Twenty-one physically active young men were randomly allocated into 2 groups: a single set group (SS, $n=10)$ and a multiple sets group (MS, $n=11)$. The single set program consisted of only 1 set of $30 \mathrm{~s}$, whereas the multiple sets comprised 3 sets of $30 \mathrm{~s}$ (rest interval between sets equaled 1 min $30 \mathrm{~s}$ ). All the water-based resistance exercises were performed at maximal effort and both groups trained twice a week for 10 weeks. Upper (bilateral elbow flexors and bilateral elbow extensors, peck deck and inverse peck deck) as well as lower-body (bilateral knee flexors and unilateral knee extensors) one-repetition maximal tests (1RM) were used to assess changes in muscle strength. The training-related effects were assessed using repeated measures two-way ANOVA ( $\alpha=5 \%)$. Both SS and MS groups increased the upper and lower-body $1 R M$, with no differences between groups. Therefore, these data show that the maximal dynamic strength significantly increases in young men after 10 weeks of training in an aquatic environment, although the improvement in the strength levels is independent of the number of sets performed.

Key words: aquatic exercises, volume, maximal dynamic strength.

\section{Introduction}

Water-based exercises comprise a series of specific movements that use water resistance to generate an overload. These exercises have been the subject of several studies in recent years and the results indicate countless benefits in both young adults (Colado et al., 2009a; Pinto et al., 2014) and elderly people (Colado et al., 2009b, 2012; Graef et al., 2010; Sanders et al., 2013). Water-based exercises promote improvements in the cardiovascular condition (Pinto et al., 2014; Takeshima et al., 2002; Taunton et al., 1996), body composition (Colado et al., 2012; Gappmaier et al., 2006; Takeshima et al., 2002), flexibility
(Takeshima et al., 2002), balance (Elbar et al., 2012; Sanders et al., 2013) and muscle strength (Ambrosini et al., 2010; Colado et al., 2009a; Graef et al., 2010; Petrick et al., 2001; Pinto et al., 2014; Pöyhönen et al., 2002; Souza et al., 2010; Takeshima et al., 2002; Tsourlou et al., 2006).

Regarding the effects of resistance training in the aquatic environment, Souza et al. (2010) showed that 11 weeks of water-based circuit resistance training improved the upper and lower limbs maximal dynamic strength (i.e., onerepetition maximal test) in untrained young women. Similarly, Colado et al. (2009a) reported a

1 - Physical Education School, Federal University of Rio Grande do Sul (UFRGS), Porto Alegre, Brazil.

2 - Physical Education School, Federal University of Pelotas (UFPel), Pelotas, Brazil. 
significant increase in upper limb maximal dynamic strength (i.e., submaximal test to estimate the one-repetition maximal value) after short-term (i.e., 8 weeks) water-based resistance training in fit young men. Pöyhönen et al. (2002) showed an increase in the isometric and isokinetic extension and flexion torques, respectively, after 10 weeks of water-based resistance training in physically active women. Moreover, Pinto et al. (2014) also demonstrated that water-based concurrent training during 12 weeks improved both maximal dynamic and isometric strength of upper and lower limbs in untrained young women.

Regarding the volume of training, the goal of studies that compared a single set with multiple sets is to evaluate whether different amounts of training produce similar increases in muscle strength. In land-based resistance training, some studies (Bottaro et al., 2009; Hass et al., 2000; Kelly et al., 2007; Kraemer et al., 2000; Marx et al., 2001; McBride et al., 2003; Ronnestad et al., 2007; Schlumberger et al., 2001) have compared programs consisting of different training volumes in young subjects. With the objective of ascertaining whether increasing the training volume (from 1 to 3 sets) would result in muscle strength improvement, Hass et al. (2000) analyzed the effects of 13-weeks of the resistance training circuit and showed that muscle strength increased in a similar fashion (8 to $14 \%$ ) in adults (recreational weightlifters) who performed 1 or 3 sets. In contrast, while analyzing a longer period of training in collegiate female tennis players, Kraemer et al. (2000) observed that multiple sets provided continuity to muscle strength gains throughout the training period (9 months), while a single set increased strength levels only during the first few weeks. However, to the authors' knowledge, no studies have compared the effects of different training volumes in the aquatic environment.

The present study was designed in order to improve the knowledge regarding the effects of different training volumes on muscle strength increases during resistance training performed in the aquatic environment. Thus, the purpose of this study was to compare the effects of single and multiple sets water-based resistance training on maximal dynamic strength in active young men. Our hypothesis was that different resistance training volumes would exhibit similar strength gains in young men.

\section{Material and Methods}

\section{Experimental design}

To investigate the hypothesis of this study, we compared the effects of water-based resistance training at different volumes (i.e., single vs. multiple sets) on maximal dynamic strength in active young men. Both single and multiple sets groups trained for 10 weeks, and each subject was evaluated before and after (weeks 0 and 11) water-based resistance training. The postmeasurements started $72 \mathrm{~h}$ after the last training session, and the subjects completed all the evaluations within a week with an interval of $48 \mathrm{~h}$ between the tests. Different tests were conducted on different days to prevent fatigue. To analyze the stability and reliability of the variables, eight subjects $(21 \pm 2.27$ years) were evaluated twice before the start of training (weeks -4 and 0 ), which served as a control period for maximal dynamic strength. Among the eight subjects who participated in the control period, three were allocated to a single set and five to a multiple sets group.

\section{Participants}

Twenty-one physically active and healthy young men, who were not engaged in any regular and systematic resistance training program in the previous 6 months, volunteered for the study after providing an informed consent form. The subjects volunteered for the present investigation following announcements in a widely read local newspaper. Exclusion criteria included any history of neuromuscular, metabolic, hormonal and cardiovascular diseases. Subjects were not taking any medication that could influence hormonal and neuromuscular metabolism and were advised not to change their nutrition practices throughout the study. Ten subjects were Physical Education students and they reported to perform different physical activities during the week. Subjects were carefully informed about the design of the study and the possible risks and discomforts related to the measurements. The research was approved by the Ethics Committee of the Federal University of Rio Grande do Sul, Brazil, and it was in accordance with the ethical standards laid down in the 1964 Declaration of Helsinki. The subjects were randomly assigned 
into two groups: single set $(\mathrm{n}=10)$ and multiple sets $(n=11)$. Two participants abandoned the intervention due to personal reasons. Therefore, 19 volunteers completed the full study schedule.

\section{Body composition}

Body mass and height were measured using an Asimed analog scale (with accuracy of $0.1 \mathrm{~kg}$ ) and an Asimed stadiometer (with accuracy of $1 \mathrm{~mm}$ ), respectively. Body composition was assessed using the skinfold technique. A 7-site skinfold equation was used to estimate body density (Jackson and Pollock, 1978), and body fat was subsequently calculated using the Siri equation (1993). In addition, the body mass index was calculated for each subject.

\section{Maximal strength}

Maximal strength was assessed using the one-repetition maximal test (1RM) on the bilateral knee flexors and unilateral knee extensors (WorldEsculptor, Porto Alegre, Brazil), bilateral elbow flexors (free-weight barbell) and bilateral elbow extensors (World-Esculptor, Porto Alegre, Brazil), peck deck and inverse peck deck (WorldEsculptor, Porto Alegre, Brazil). The 1RM value was considered as the maximal load that could be exerted at the concentric phase for a given exercise. One week prior to the test day, subjects were familiarized with all procedures in 2 sessions. On the test day, the subjects warmed up for $5 \mathrm{~min}$ on a cycle ergometer, stretched all major muscle groups, and performed specific movements for the exercise test. Each subject's maximal load was determined with no more than 5 attempts with a 2-3 min recovery between attempts. Performance time for each contraction (concentric and eccentric) was $2 \mathrm{~s}$, controlled by an electronic metronome (MA-30, KORG, Tokyo, Japan). The 1RM was measured during two days (i.e., three exercises each day) with an interval of $48 \mathrm{~h}$ and all 1RM procedures were previously described by Cadore et al. (2010). The test-retest reliability coefficient (intraclass correlation coefficient, ICC) was 0.93 for the knee flexors 1RM and 0.69 for the knee extensors 1RM, 0.95 for the elbow flexors $1 \mathrm{RM}$ and 0.95 for the elbow extensors $1 \mathrm{RM}$ and 0.99 for the peck deck 1RM and 0.96 for the inverse peck deck 1RM. Each specific test at pre- and post-intervention was supervised by the same investigator, who was blinded to the training group of the subjects. The tests were conducted with the same equipment and identical subject/equipment positioning.

\section{Water-based resistance training}

The sample followed a callisthenic (nonuse of aquatic devices) water-based exercise program during 10 weeks. Subjects of the study trained 2 times a week, on nonconsecutive days. Training groups were differentiated by the exercise volume during the water-based resistance training. One group performed a single set (SS - 1 set of $30 \mathrm{~s}$ ) and the other one performed multiple sets (MS - 3 sets of $30 \mathrm{~s}$ ) of each resistance exercise. The total time per session spent by SS and MS was 25 and $50 \mathrm{~min}$, respectively. Before the start of the water-based resistance training, subjects completed 2 familiarization sessions in the water environment to practice the exercises they would further perform during the training period as described by Pinto et al. (2014). Moreover, instructions about the rating of perceived exertion (RPE) scale were explained to the participants (Borg, 1990). The subjects performed the water-based resistance exercises progressively at all effort levels to familiarize themselves with the minimal effort and progression until they could reach maximal effort at their own pace.

The water-based resistance training was composed by upper and lower limbs exercises and by exercise for the abdominal musculature. The resistance exercises were divided into a circuit in both SS and MS groups. The pool was divided into four stations, and in each one the subjects performed 3 exercises, 12 exercises in total. After the performance of a set of each of the 3 exercises, an active rest interval of $1 \mathrm{~min} 30 \mathrm{~s}$ was taken, in which the subjects kept a stationary running exercise at an intensity equivalent to the perception 9 of the Borg scale (Borg, 1990). After the rest interval, the subjects of the SS group changed stations while the subjects of the MS group repeated the sequence of each station 3 times. The exercises used in the water-based resistance training are described in Table 1.

The exercises performed during the warm-up (i.e., $5 \mathrm{~min}$ ) and the cool-down (i.e., 8 min) were standardized to avoid any possible interference with the aims of the study. Two experienced water-based instructors carefully supervised all training sessions. During the resistance exercises, the individuals were instructed to perform each repetition at maximal 
effort and amplitude in order to achieve the greatest velocity of motion as possible, and consequently, greater resistance. Verbal encouragement was provided during all resistance training sessions by the same instructor. Throughout the training period, the water temperature was maintained at $31.0 \pm 0.1{ }^{\circ} \mathrm{C}$. In addition, the water depth for each subject was fixed between the xiphoid process and shoulders.

\section{Statistical analysis}

Results are reported as mean \pm SD. Normaldistribution and homogeneity parameters were checked with Shapiro-Wilk and Levene tests, respectively. Statistical comparisons in the control period (from weeks -4 to 0 ) were performed by using Student paired $t$ tests. In addition the test-retest reliability for each 1RM test between the weeks -4 to 0 was determined using the intraclass correlation coefficient (ICC). The training-related effects were assessed using repeated measures 2-way ANOVA (factors: group and time). Significance was accepted when $\alpha=5 \%$, and the SPSS statistical software package (version 17.0) was used to analyze all data.

\section{Results}

The demographic characteristics of the remaining subjects ( $S S n=10 ; M S n=9$ ) included in the data analysis were as follows (mean $\pm \mathrm{SD}$ ): SS age $22 \pm 3.8$ years, body mass $76.5 \pm 13.4 \mathrm{~kg}$, body height $1.8 \pm 0.1 \mathrm{~m}$, percent fat $24.7 \pm 16.4 \%$, body mass index $24.7 \pm 4 \mathrm{~kg} / \mathrm{m}^{2}$; MS age $21.4 \pm 3$ years, body mass $78.4 \pm 11.2 \mathrm{~kg}$, body height $1.8 \pm 0.1 \mathrm{~m}$, percent fat $18.9 \pm 11.3 \%$, body mass index $24.3 \pm$ $3.8 \mathrm{~kg} / \mathrm{m}^{2}$.

Table 1

Single (SS) and multiple sets (MS) water-based resistance training

\begin{tabular}{|c|c|c|}
\hline Sets/Duration & Exercise name & Description of the joint movements \\
\hline \multirow{3}{*}{$\begin{array}{l}\text { Station } 1 \\
\text { SS } 1 \text { set } 30 \mathrm{~s} \\
\text { MS } 3 \text { sets } 30 \mathrm{~s}\end{array}$} & Hip adduction/abduction & Hip adduction and abduction (simultaneously). \\
\hline & $\begin{array}{l}\text { Horizontal shoulder } \\
\text { flexion/extension }\end{array}$ & $\begin{array}{l}\text { Horizontal shoulder flexion and extension } \\
\text { (simultaneously). }\end{array}$ \\
\hline & Lateral crunch & $\begin{array}{l}\text { Trunk lateral flexion and extension in horizontal } \\
\text { position, with a noodle supporting the back (alternately } \\
\text { left and right side). }\end{array}$ \\
\hline \multirow[t]{3}{*}{$\begin{array}{l}\text { Station } 2 \\
\text { SS } 1 \text { set } 30 \mathrm{~s} \\
\text { MS } 3 \text { sets } 30 \mathrm{~s}\end{array}$} & $\begin{array}{l}\text { Frontal kick and slide } \\
\text { back with the right leg }\end{array}$ & $\begin{array}{l}\text { The first phase of the movement consisted of a right hip } \\
\text { flexion at } 90^{\circ} \text {, with right knee extension; the second } \\
\text { phase consisted of a right hip and knee extension. }\end{array}$ \\
\hline & $\begin{array}{l}\text { Frontal kick and slide } \\
\text { back with the left leg }\end{array}$ & $\begin{array}{l}\text { The first phase of the movement consisted of a left hip } \\
\text { flexion at } 90^{\circ} \text {, with left knee extension; the second phase } \\
\text { consisted of a left hip and knee extension. }\end{array}$ \\
\hline & Frontal crunch 2-times & $\begin{array}{l}\text { Trunk flexion and extension in horizontal position } \\
\text { performed in 2-times, with a noodle supporting the } \\
\text { back. }\end{array}$ \\
\hline \multirow{3}{*}{$\begin{array}{l}\text { Station } 3 \\
\text { SS } 1 \text { set } 30 \mathrm{~s} \\
\text { MS } 3 \text { sets } 30 \mathrm{~s}\end{array}$} & $\begin{array}{l}\text { Knee flexion/extension } \\
\text { with the right leg }\end{array}$ & $\begin{array}{l}\text { Right knee flexion and extension (starting from hip } \\
\left.\text { flexion at } 90^{\circ}\right) \text {. }\end{array}$ \\
\hline & $\begin{array}{l}\text { Knee flexion/extension } \\
\text { with the left leg }\end{array}$ & $\begin{array}{l}\text { Left knee flexion and extension (starting from hip flexion } \\
\text { at } 90^{\circ} \text { ). }\end{array}$ \\
\hline & $\begin{array}{c}\text { Shoulder } \\
\text { adduction/abduction } \\
\end{array}$ & Shoulder adduction and abduction (simultaneously). \\
\hline \multirow{3}{*}{$\begin{array}{l}\text { Station } 4 \\
\text { SS } 1 \text { set } 30 \mathrm{~s} \\
\text { MS } 3 \text { sets } 30 \mathrm{~s}\end{array}$} & $\begin{array}{l}\text { Elbow flexion/extension } \\
\text { with the right arm }\end{array}$ & $\begin{array}{l}\text { Right elbow flexion and extension (starting from the } \\
\text { anatomical position). }\end{array}$ \\
\hline & $\begin{array}{c}\text { Elbow flexion/extension } \\
\text { with the left arm }\end{array}$ & $\begin{array}{l}\text { Left elbow flexion and extension (starting from the } \\
\text { anatomical position). }\end{array}$ \\
\hline & Frontal crunch & $\begin{array}{l}\text { Trunk flexion and extension performed in the horizontal } \\
\text { position, with a noodle supporting the back. }\end{array}$ \\
\hline
\end{tabular}


Table 2

Pre and post values during the control period ( -4 and 0 weeks)

\begin{tabular}{lccccc}
\hline & \multicolumn{5}{c}{ Subjects n=8 } \\
\cline { 2 - 6 } & \multicolumn{2}{c}{ Week -4} & & Week 0 \\
\hline & 32.37 & \pm 4.50 & 34.00 & \pm 5.34 & 0.075 \\
\hline EFLE 1RM (kg) & 55.50 & \pm 7.78 & 59.87 & \pm 8.44 & $<0.001^{*}$ \\
EEX 1RM (kg) & 65.12 & \pm 10.64 & 67.12 & \pm 11.85 & $0.025^{*}$ \\
KFLE 1RM (kg) & 68.37 & \pm 7.42 & 66.62 & \pm 9.16 & 0.578 \\
KEX 1RM (kg) & 54.00 & \pm 11.98 & 52.87 & \pm 10.89 & 0.450 \\
PD 1RM (kg) & 63.75 & \pm 9.47 & 67.12 & \pm 11.93 & $0.038^{*}$ \\
IPD 1RM $(\mathrm{kg})$ & & & & &
\end{tabular}

EFLE and EEX 1RM, elbow flexors and elbow extensors one maximal repetition; KFLE 1RM and KEX 1RM, knee flexors and knee extensors one maximal repetition; PD 1RM and IPD 1RM, peck deck and inverse peck deck one maximal repetition.

* indicate significant difference between week -4 and 0.

Table 3

Strength performance before and after training: water-based single set and water-based multiple sets; mean $\pm S D$

\begin{tabular}{|c|c|c|c|c|c|c|c|c|c|c|c|}
\hline & \multicolumn{4}{|c|}{ Single Set, $\mathrm{n}=10$} & \multicolumn{4}{|c|}{ Multiple Sets, n=9 } & \multirow{3}{*}{$\begin{array}{c}\text { Group } \\
p\end{array}$} & \multirow{3}{*}{$\begin{array}{c}\text { Time } \\
p\end{array}$} & \multirow{3}{*}{$\frac{\text { Group*Time }}{\mathrm{p}}$} \\
\hline & \multicolumn{2}{|c|}{ Pre } & \multicolumn{2}{|c|}{ Post } & \multicolumn{2}{|c|}{ Pre } & \multicolumn{2}{|c|}{ Post } & & & \\
\hline & Mean & SD & Mean & SD & Mean & SD & Mean & SD & & & \\
\hline $\begin{array}{l}\text { EFLE } \\
1 \mathrm{RM}(\mathrm{kg})\end{array}$ & 31.40 & \pm 5.08 & 32.80 & \pm 4.39 & 35.67 & \pm 5.17 & 37.22 & \pm 4.66 & 0.064 & $<0.001^{*}$ & 0.820 \\
\hline $\begin{array}{l}\text { EEX 1RM } \\
(\mathrm{kg})\end{array}$ & 58.40 & \pm 11.13 & 60.50 & \pm 9.28 & 64.33 & \pm 8.99 & 69.33 & \pm 8.87 & 0.108 & $0.001^{*}$ & 0.104 \\
\hline $\begin{array}{l}\text { KFLE } \\
1 \text { RM (kg) }\end{array}$ & 62.60 & \pm 12.84 & 70.10 & \pm 13.57 & 67.11 & \pm 8.78 & 74.44 & \pm 10.14 & 0.134 & $0.001^{*}$ & 0.143 \\
\hline $\begin{array}{l}\text { KEX 1RM } \\
(\mathrm{kg})\end{array}$ & 67.90 & \pm 9.48 & 74.40 & \pm 12.70 & 67.89 & \pm 9.31 & 74.37 & \pm 11.59 & 0.133 & $0.001^{*}$ & 0.755 \\
\hline $\begin{array}{l}\text { PD 1RM } \\
(\mathrm{kg})\end{array}$ & 50.40 & \pm 13.32 & 51.90 & \pm 13.08 & 58.33 & \pm 10.58 & 61.67 & \pm 11.87 & 0.994 & $<0.001^{*}$ & 0.985 \\
\hline $\begin{array}{l}\text { IPD 1RM } \\
(\mathrm{kg})\end{array}$ & 63.80 & \pm 14.24 & 68.60 & \pm 13.13 & 73.22 & \pm 12.72 & 77.33 & \pm 10.32 & 0.410 & $<0.001^{*}$ & 0.932 \\
\hline
\end{tabular}

EFLE and EEX 1RM, elbow flexors and elbow extensors one maximal repetition; KFLE 1RM and KEX 1RM, knee flexors and knee extensors one maximal repetition;

$P D$ IRM and IPD 1RM, peck deck and inverse peck deck one maximal repetition.

* indicate significant difference between pre and post training in both groups (single and multiple sets). 
During the control period (weeks -4 and 0), no changes were observed in most variables analyzed (Table 2). However, slight changes were found for the elbow extensors, knee flexors and inverse peck deck 1RM between weeks -4 and 0 . No significant differences were observed in training compliance between SS and MS (91.36 \pm 8.69 vs. $90.40 \pm 8.33 \%$, respectively). In addition, there were no differences between groups before training in age $(\mathrm{p}=0.729)$, body mass $(\mathrm{p}=0.747)$, body height $(\mathrm{p}=0.203)$, percent fat $(\mathrm{p}=0.386)$ and body mass index $(\mathrm{p}=0.790)$.

At baseline, there were no differences between groups in bilateral knee flexors and unilateral knee extensors 1RM, bilateral elbow flexors and bilateral elbow extensors 1RM, as well as peck deck and inverse peck deck 1RM. After training, there were increases in bilateral knee flexors (SS: $12.30 \pm 7.82$ vs. MS: $11.00 \pm 6.58 \%$ ) and unilateral knee extensors 1RM (SS: $9.60 \pm 10.86$ vs. MS: $9.51 \pm 6.57 \%$ ), bilateral elbow flexors (SS: 5.10 \pm 5.51 vs. MS: $4.79 \pm 5.42 \%$ ), bilateral elbow extensors 1RM (SS: $4.79 \pm 9.99$ vs. MS: $7.98 \pm$ $4.23 \%$ ), peck deck (SS: $3.41 \pm 5.50$ vs. MS: $5.58 \pm$ $4.01 \%$ ) and inverse peck deck 1RM (SS: $7.73 \pm 9.75$ vs. MS: $6.50 \pm 8.06 \%$ ) in both SS and MS, with no statistically significant difference between groups. These results are described in Table 3.

\section{Discussion}

The primary finding of this study was that the training volume was not a determining factor for greater muscle strength increments, since the SS group exhibited similar strength gains compared to the MS group.

The results of this study demonstrated that young men after 10 weeks of training in an aquatic environment increased maximal dynamic strength of upper and lower limbs. These data are in agreement with some previous studies on resistance training in the aquatic environment (Colado et al., 2009a; Pinto et al., 2014). In the only previous study (Colado et al., 2009a) that assessed 8 weeks of water-based resistance training in young men a $5 \%$ increase in muscle strength on the flat bench press was found. The results of the present study are in agreement with the study of Colado et al. (2009a), since we found 3 and 5\% increases in 1RM of peck deck in the SS and MS group, respectively. Similarly, Souza et al. (2010) analyzed the effects of 11 weeks of water-based resistance training on maximal dynamic strength of several muscle groups in untrained young women. In support of the results of the present study, these authors observed significant increases in muscle strength for all exercises assessed (i.e., bench press: $25 \%$, knee extension: $20 \%$; knee flexion: $17 \%$ and seated row: $12 \%$ ). However, the goal of the previous studies was not to compare the volume of training on muscle strength, as the period of training was divided into different mesocycles. Thus, the differences observed between these strength gains percentages may be explained by the periodization model adopted in the present study, where the volume was kept constant, as our goal was to assess the different effects of training using 1 or 3 sets. Moreover, the effects of resistance training depend on subjects' training backgrounds (i.e., untrained young women vs. physically active young men).

In the literature reviewed, no studies comparing different training volumes in the aquatic environment were found; only land-based studies have been performed to address this subject. Thus, a comparison with land-based studies was deemed necessary. Previous studies have shown (Cannon and Marino, 2010; Hass et al., 2000; Kraemer et al., 2000; Radaelli et al., 2013; Starkey et al., 1996) that SS can be considered an alternative to MS training, as this approach saves time and generates similar strength increments. Some of these studies were included in the metaanalysis performed by Fröhlich and Emrich (2010), which identified 72 studies published between 1985 and 2008. The results of this metaanalysis support those of the present research, as the authors stated that for short-term interventions, such as the 10-week duration of this study, the effects of training were identical for both groups. However, for long-term observations, MS training may be suggested for trained individuals who seek additional muscle strength gains. Nevertheless, the study developed by Schlumberger et al. (2001) showed that shortterm intervention (i.e., 6-week) presented greater percentage strength gains for the bilateral leg extension 1RM in women with basic experience in resistance training (3-6 months) in the multiple sets group compared to the single set resistance training group (15\% vs. $6 \%$ ).

According to Hass et al. (2001), additional 
sets do not produce significant improvements in muscle strength after 13 weeks of training using land-based circuits in adult recreational weight lifters. The aim of this previous study was to confirm whether increasing the training volume (from 1 to 3 sets) would result in increases in muscle strength, and the results showed a similar increase in muscle strength for leg extension (14\% vs. $13 \%)$, leg curl ( $9 \%$ vs. $12 \%$ ) and chest press $(12 \%$ vs. $13 \%)$ among subjects whose training included 1 or 3 sets. Also similar to this previously cited study, McBride et al. (2003) concluded that untrained individuals (men and women) who trained for 1 set and those who trained for 6 sets presented similar percentage gains in muscle strength on leg press exercise after 12 weeks of training ( $41 \%$ vs. $53 \%$ ). The results of the present study are in line with the aforementioned studies, since similar percentage gains in muscle strength were found in fit young men that trained 1 or 3 sets in water-based resistance training (i.e., bilateral knee flexors 1RM SS: $12 \%$ vs. MS: $11 \%$; unilateral knee extensors 1RM SS: $10 \%$ vs. MS: $9 \%$; peck deck 1RM SS: $3 \%$ vs. MS: $5 \%$ ). However, Marx et al. (2001) found that the high-volume training (MS) was superior to the low-volume training (SS) for muscle performance increases in non-trained women. As the training duration is increased beyond 10 weeks, the dynamics of neural and hypertrophic relationships are inverted, i.e., muscle hypertrophy is predominant, and its contribution to increases in strength and power becomes greater than that of neural factors. Therefore, the difference in these results may have been due to the longer period of training, i.e., 24 weeks, as compared to 10 weeks in the present study.

A possible limitation of the present study was that the participants performed a water-based resistance training composed of sets lasting $30 \mathrm{~s}$, which could induce greatest changes in muscle endurance, and only maximal strength was assessed in this study. Thus, it is possible that differences between single vs. multiple sets waterbased resistance training could occur if a specific test for muscle endurance would be performed, which remains speculative. In addition, the sample size could be a limitation, since only 10 young men composed the single set group and 9 the multiple sets group.

In summary, the results of the present study showed that the upper and lower limbs maximal dynamic strength significantly increased in young men after 10 weeks of water-based resistance training. In addition, the improvement in the strength levels was independent of the number of sets performed (i.e., single vs. multiple sets). Regarding the practical importance of our findings, we found that single or multiple sets water-based resistance training in young active men exhibited similar maximal dynamic strength increases in upper and lower limbs. If a subject focuses on aerobic exercises (i.e., weight reduction), single set water-based resistance training may be a time-efficient supplement for increasing strength. Moreover, a short training session composed by only 1 set per exercise may help to avoid a high dropout rate in water-based resistance training when subjects are unwilling to perform longer resistance training sessions.

\section{Acknowledgements}

The authors gratefully acknowledge CAPES and CNPq Brazilian Government Associations for supporting this study. We also gratefully acknowledge all subjects who participated in this research and made this project possible.

\section{References}

Ambrosini AB, Brentano MA, Coertjens M, Kruel LFM. The effects of strength training in hydrogymnastics for middle-age women. Int J Aquat Res Educ, 2010; 4: 153-162

Bottaro M, Veloso J, De Salles BF, Simo R, Celes R, Brown LE. Early phase adaptations of single vs. multiple sets of strength training on upper and lower body strength gains. Isokinetics and Exercise Science, 2009; 17: 207-212

Borg G. Psychophysical scaling with applications in physical work and the perception of exertion. Scand J Work Environ Health, 1990; 16: 55-58 
Cadore EL, Pinto RS, Lhullier FLR, Correa CS, Alberton CL, Pinto SS, Almeida APV, Tartaruga MP, Silva EM, Kruel LFM. Physiological effects of concurrent training in elderly men. Int J Sports Med, 31: 689697

Cannon J, Marino FE. Early-phase neuromuscular adaptations to high- and low-volume resistance training in untrained young and older women. J Sports Sci, 2010; 28: 1505-1514

Carpinelli RN, Otto RM. Strength training: Single versus multiple sets. Sports Med, 1998; 26: 73-84

Colado JC, Tella V, Triplett NT, Gonzalez LM. Effects of a short-term aquatic resistance program on strength and body composition in fit young men. J Strength Cond Res, 2009a; 23: 549-559

Colado JC, Triplett NT, Tella V, Saucedo P, Abellan J. Effects of aquatic resistance training on health and fitness in postmenopausal women. Eur J Appl Physiol, 2009b; 106: 113-122

Colado JC, Garcia-Masso X, Rogers ME, Tella V, Benavent J, Dantas EH. Effects of aquatic and dry land resistance training devices on body composition and physical capacity in postmenopausal women. $J$ Hum Kinet, 2012; 32: 185-Q95

Elbar O, Tzedek I, Vered E, Shvarth G, Friger M, Melzer I. A water-based training program that includes perturbation exercises improves speed of voluntary stepping in older adults: a randomized controlled cross-over trial. Arch Gerontol Geriatr, 2013; 56: 134-140

Fröhlich M, Emrich E. Outcome Effects of Single-Set Versus Multiple-Set Training - An Advanced Replication Study. Res Sports Med, 2010; 18: 157-175

Gappmaier E, Lake W, Nelson AG, Fisher AG. Aerobic exercise in water versus walking on land: Effects on indices of fat reduction and weight loss of obese women. J Sports Med Phys Fitness, 2006; 46: 564-569

Graef FI, Pinto RS, Alberton CL, de Lima WC, Kruel LFM. The effects of resistance training performed in water on muscle strength in the elderly. J Strength Cond Res, 2010; 24: 3150-3156

Hass CJ, Garzarella L, De Hoyos D, Pollock ML. Single versus multiple sets in long-term recreational weightlifters. Med Sci Sports Exerc, 2000; 32: 235-242

Jackson AS, Pollock ML. Generalized equations for predicting body density of men. Brit J Nutr, 1978; 40: 497504

Kelly SB, Brown LE, Coburn JW, Zinder SM, Gardner LM, Nguyen D. The effect of single versus multiple sets on strength. J Strength Cond Res, 2007; 21: 1003-1006

Kemmler WK, Lauber D, Engelke K, Weineck J. Effects of single- vs. multiple-set resistance training on maximum strength and body composition in trained postmenopausal women. J Strength Cond Res, 2004; 18: 689-694

Kraemer WJ, Ratamess N, Fry AC, Triplett-Mcbride T, Koziris LP, Bauer JA, Lynch JM, Fleck SJ. Influence of resistance training volume and periodization on physiological and performance adaptations in collegiate women tennis players. Am J Sports Med, 2000; 28: 626-633

Marx JO, Ratamess NA, Nindl BC, Gotshalk LA, Volek JS, Dohi K, Bush JA, Gómez AL, Mazzetti SA, Fleck SJ, Häkkinen K, Newton RU, Kraemer WJ. Low-volume circuit versus high-volume periodized resistance training in women. Med Sci Sports Exerc, 2001; 33: 635-643

McBride JM, Blaak JB, Triplett-Mcbride T. Effect of resistance exercise volume and complexity on EMG, strength, and regional body composition. Eur J Appl Physiol, 2003; 90: 626-632

Petrick M, Paulsen T, George J. Comparison between quadriceps muscle strengthening on land and in water. Physiotherapy, 2001; 87: 310-317

Pinto SS, Cadore EL, Alberton CL, Zaffari P, Bagatini NC, Baroni BM, Radaelli R, Lanferdini FJ, Colado JC, Pinto RS, Vaz MA, Bottaro M, Kruel LFM. Effects of intra-session exercise sequence during waterbased concurrent training. Int J Sports Med, 2014; 35: 41-48

Pöyhönen T, Sipilä S, Keskinen KL, Hautala A, Savolainen J, Mälkiä E. Effects of aquatic resistance training on neuromuscular performance in healthy women. Med Sci Sports Exerc, 2002; 34: 2103-2109 
Radaelli R, Botton CE, Wilhelm EN, Bottaro M, Lacerda F, Gaya A, Moraes K, Peruzzolo A, Brown LE, Pinto RS. Low- and high-volume strength training induces similar neuromuscular improvements in muscle quality in elderly women. Exp Gerontol, 2013; 48: 710-716

Rhea MR, Alvar BA, Burkett LN. Single versus multiple sets for strength: A meta-analysis to address the controversy. Res Q Exerc Sport, 2002; 73: 485-488

Ronnestad BR, Egeland W, Kvamme NH, Refsnes PE, Kadi F, Raastad T. Dissimilar effects of one- and threeset strength training on strength and muscle mass gains in upper and lower body in untrained subjects. J Strength Cond Res, 2007; 21: 157-163

Sanders ME, Takeshima N, Rogers ME, Colado JC, Borreani S. Impact of the S.W.E.A.T. ${ }^{\mathrm{M}}$ water-exercise method on activities of daily living for older women. J Sports Sci Med, 2013; 12: 707-715

Schlumberger A, Stec J, Schmidtbleicher D. Single- vs. Multiple-Set Strength Training in Women. J Strength Cond Res, 2001; 15: 284-289

Siri WE. Body composition from fluid spaces and density: analysis of methods. Nutrition, 1993; 9: 480-491

Souza AS, Rodrigues BM, Hirshammann B, Graef FI, Tiggemann CL, Kruel LFM. Aquatic strength training in young women. Motriz, 2010; 16: 649-657

Starkey DB, Pollock ML, Ishida Y, Welsch MA, Brechue WF, Graves JE, Feigenbaum MS. Effect of resistance training volume on strength and muscle thickness. Med Sci Sports Exerc, 1996; 28: 1311-1320

Takeshima N, Rogers ME, Watanabe WF, Brechue WF, Okada A, Yamada T, Islam MM, Hayano J. Waterbased exercise improves health-related aspects of fitness in older women. Med Sci Sports Exerc, 2002; 34: 544-551

Taunton JE, Rhodes EC, Wolski LA, Donelly M, Warren J, Elliot J, McFarlane L, Leslie J, Mitchell J, Lauridsen B. Effect of land-based and water-based fitness programs on the cardiovascular fitness, strength and flexibility of woman aged 65-75 years. Gerontology, 1996; 42: 204-210

Tsourlou T, Benik A, Dipla K, Zafeiridis A, Kellis S. The effects of a twenty-four-week aquatic training program on muscular strength performance in healthy elderly women. J Strength Cond Res, 2006; 20: $811-818$

\section{Corresponding author:}

\section{Stephanie Santana Pinto}

Physical Education School, Federal University of Pelotas (UFPel)

Rua Luiz de Camões, 625 - Tablada

96055-630 Pelotas, RS, Brazil

Phone: 5553 3273-2752

Fax: 5553 3273-3851

E-mail: tetisantana@yahoo.com.br 